\title{
PBL Online Learning in Thermodynamics and Statistical Physics: Students' Readiness
}

\author{
Elnetthra Folly Eldy, Fauziah Sulaiman
}

\begin{abstract}
This paper explores students' readiness towards $P B L$ online learning in two subjects of Physics among Physics students from Universiti Malaysia Sabah. Online learning was implemented through Problem-Based Learning (PBL) approach in two subjects, i.e., Thermodynamics Physics and Statistical Physics each during on Semester 1 and 2 respectively. A set of questionnaire was distributed to twenty five (25) second-year students of Physics with Electronics at University Malaysia Sabah before and after online learning was implemented for 28 weeks long. As a supplement, an interview was held with selected group of students from this sample to study students' technical and pedagogical readiness which was discussed in this paper. As a conclusion, results of this paper lays the general foundation for active implementation of PBL online in topics of Physics in Universiti Malaysia Sabah.
\end{abstract}

Keywords : Online Learning readiness, PBL online learning, Problem-based Learning

\section{INTRODUCTION AND STUDY REVIEWS ON IMPORTANT STUDY ON STUDENTS' READINESS TOWADS LEARNING THROUGH PBL ONLINE}

$\mathrm{O}_{\text {nline learning in this study described as a learning and }}$ teaching process occupied with the use of network information, communications technology, flexibility of connectivity to stimulate interaction [1], [2]. This is also in line with study by [3] as online learning define as the use of technology (i.e., internet, computer or mobile phone) to design, deliver, select and administer of individualized comprehensive and dynamic content in real time.

Thus, with government and higher institution interested in the structure of online learning and research study has been highlighted in these recent years, the future of online learning is optimistic however curricular must be flexible as new generations are question on their advancement in skills and career and relations with their study [4]. Other than that, the features of facilities for utilizes online learning should hand in hand by government and higher institutional [5].

The conduction of problem based learning (PBL) usually in a face-to-face and the use of PBL in electronic-based distance-education are rare and less known [6]. However, as online learning cooperative with PBL gives advantages such as increased higher-order learning and enhance student

Revised Manuscript Received on September 22, 2019

* Correspondence Author

Elnetthra Folly Eldy, Preparatory Centre for Science and Technology, Universiti Malaysia Sabah, Kota Kinabalu, Sabah, Malaysia. Email:

Fauziah Sulaiamn, Physics with Electronics Programme, Faculty of Science and Natural Resources, Universiti Malaysia Sabah, Kota Kinabalu, Sabah, Malaysia. Email: fauziahs@ums.edu.my elnetthra@ums.edu.my

understanding, contributed to students' performance and improve their skills such as information and engagement with their learning [3], [7], allowed PBL to conducted in online learning.

However, even PBL online is flexible, it can also be very challenging so, in order to implement and achieve better result with the introduction of PBL online especially among Physics students, their readiness were vital to study [5]. This study also formed due to rare and less study on students' readiness towards online learning I Physics compare to other subject such as Mathematics, Biology or other basic science among undergraduate students. Reference [8] present the three (3) category factors of readiness towards online learning; technical, lifestyle and pedagogical readiness. Technical readiness includes aspect such as connectivity, hardware, software and technical support is one of the vital factors towards online learning. Lifestyle readiness on the other hand, is related to environment such as expertise, culture, instructions and rules. Finally, pedagogical readiness is about self-motivated, independent learners and self-confident.

As an addition, several study on students' readiness towards online based learning such as [9] - [11] in their study listed several factors contribute to students' readiness towards online learning such as institutional factor which includes the facilities provided by institutional to boost online learning activities, students behavior and attitudes, students interactive applications included the idea of online learning enable them to shared information with each other, clear and better characteristics of instructions encourage students' motivation and technology and system factor.

\section{METHODOLOGY AND MATERIALS}

\section{A. Study Design and Data Collection Tools}

The survey was to give an idea the readiness towards problem-based learning through online among students with Physics as their field of study. A set of survey questionnaire with three (3) themes; anxiety, individuality of learning and self-motivating learning was distributed to 25 second year students of Physics with Electronics at the same institute before and after the intervention of online PBL introduced. This questionnaire is set as close-ended question which divided into five (5) points of Likert Scale, from 1 representing strongly agree to 5 representing strongly disagree. In addition, interview was held with few students from these sample to further understand their feedback towards this implementation. 
PBL is one part of the assessment for both subject, Statistical Physics and Thermodynamics among the other. The basic structure of PBL practices in this study is similar from Maastricht Steps. These steps emphasized the seven (7) steps which is clarify, define, analyse, review, identify learning objectives and report and synthesis [12], [13]. As for this study, all of these steps was performed online through Facebook. Figure 1 shows the flow chart of implementation PBL online in details to 25 students for Statistical Physics and Thermodynamics in two semester respectively.

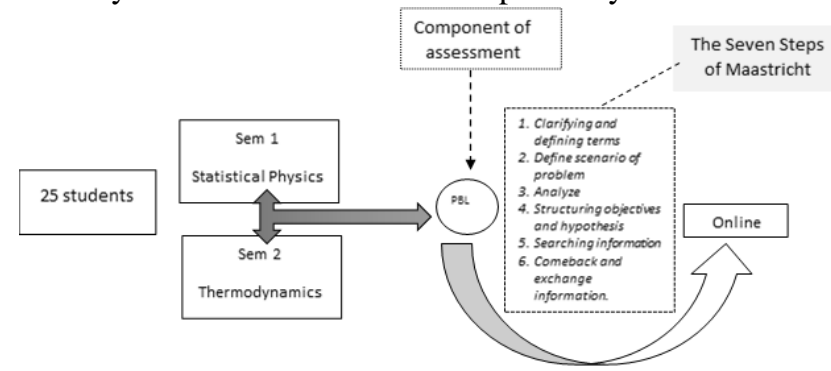

Fig. 1. Flow chart of implementation PBL online

\section{B. Population and Study Area}

The subject of this study was 25 students consists of 16 females and 9 males enrolled in their second year of Physics with Electronics programmed in Universiti Malaysia Sabah (UMS). All students was compulsory to sit for Thermodynamics Physics and Statistical Physics in Semester 1 and Semester 2 continuously, three (3) credit hours each. For 28 weeks and 14 weeks on each course, problem-based learning was exposed to these students through online learning. Student's age was ranged in between 20 to 23 years old with mean of the age is 22.24 years old and $68 \%(\mathrm{~N}=17)$ of them was staying inside campus where internet was 24 hours accessible.

\section{Online Platform}

The online discussion in this study was implemented using social network Facebook as platform. Facebook chosen as it is easier accessed by anyone and one of the ideal potential platforms for online discussion in this study. For instance, study by [14] show how Facebook might become of the online based mechanism, this is due to the ability of Facebook fostering active participation among students compared to LMS when it is used for implement an online learning.

\section{RESULTS AND FINDINGS}

The results and findings in this paper will be presented and further discuss in three (3) main part, the demographic data, students' technical readiness and students' pedagogical readiness.

\section{A. Students' Demographic Data}

This students' demographic survey which enclosed in Table 1 designed as open-ended questions was distributed before students introduced with problem-based learning through online learning. This survey was disclosed to study on their basic background and background on numerous elements such as gender, age, accessible on internet connection and personal computer.

There are 9 male and 16 female students who involved in this study. This small number of students is depending on students enrolled for Physics with Electronics in Universiti Malaysia Sabah. Majority of the students claimed to have personal computer at home $(96 \%)$ and internet connection at home $(88 \%)$.

\section{B. Students' Technical Readiness}

Technical readiness in this study will focused on students' comfort with technical aspect, such as learning, working and communicate with computer and via online.

\section{Comfortable in Communication}

Students show neutral feeling towards communication through their interview transcript when online learning implemented in their PBL intervention Students found sometime it is hard to deliver the explanations through online rather prefer by face-to-face. Constraints in term of language is one of the factor contribute to students felt comfortable explain face-to-face with their peers.

Students: Since online learning does not require us to attend class, sometimes face-to-face discussions will be held individually to make sure everyone understand what is being discussed online. Face-to-face communications is much easier to explain.

This is also discuss in study by [15], stated there was a conflict between the students own searching process and understanding with the whole group. Hence, it is also indicated the importance of other interactions such as face to face.

\section{Trust Issues on Online Learning}

Results of this study shows that students felt trust towards online learning as majority felt comfortable sharing their knowledge, information, exchange source through online and managing file on or offline. This can be seen in their following interview transcript:

Students: Learning through online also didn't provide us to print any information source to share with other members, we could just need to share the link and everyone has the access to read it.

The transcript indicates students have no problem sharing their sources of information to others through online. In contrast with report study by [15] shows students stated originally reluctant on transition to online learning and does not really agree on being comfortable working with computer. However, study by Jun Jin also report how students eventually swayed to online learning over a period of implementation.

\section{Students' Pedagogical Readiness}

Pedagogical readiness in this study will focused on students' self-confident, communication and social presence 
Table- I: Students readiness on PBL in Physics

\begin{tabular}{|c|c|c|c|c|c|c|c|}
\hline Item & Component & 1 & 2 & 3 & 4 & 5 & $\begin{array}{l}\text { Mea } \\
\mathrm{n}\end{array}$ \\
\hline 1 & $\begin{array}{l}\text { I feel I am able to get the } \\
\text { benefits from group } \\
\text { learning and individual } \\
\text { learning in PBL process }\end{array}$ & 0 & 0 & 7 & $\begin{array}{l}1 \\
5\end{array}$ & 3 & 3.84 \\
\hline 2 & $\begin{array}{lll}\text { I feel enjoyed } & \text { and } \\
\text { treasure } & \text { during } & \text { PBL } \\
\text { process } & & \end{array}$ & 0 & 2 & 7 & $\begin{array}{l}1 \\
3\end{array}$ & 5 & 4.08 \\
\hline 3 & $\begin{array}{l}\text { I feel I can cooperatively } \\
\text { within my group } \\
\text { members }\end{array}$ & 0 & 0 & 7 & $\begin{array}{l}1 \\
3\end{array}$ & 5 & 3.92 \\
\hline 4 & $\begin{array}{l}\text { I am able to increase my } \\
\text { friendship between the } \\
\text { members }\end{array}$ & 0 & 2 & 2 & $\begin{array}{l}1 \\
1\end{array}$ & 1 & 4.16 \\
\hline 5 & $\begin{array}{l}\text { I am able to develop } \\
\text { friendships }\end{array}$ & 1 & 1 & 2 & $\begin{array}{l}1 \\
2\end{array}$ & 9 & 4.08 \\
\hline 6 & $\begin{array}{l}\text { I am able to create } \\
\text { interaction between } \\
\text { member or new friend }\end{array}$ & 1 & 1 & 3 & $\begin{array}{l}1 \\
0\end{array}$ & 0 & 4.08 \\
\hline 7 & $\begin{array}{l}\text { I can communicated well } \\
\text { with others and } \\
\text { demonstrated enthusiasm } \\
\text { for projects }\end{array}$ & 1 & 0 & 5 & $\begin{array}{l}1 \\
3\end{array}$ & 5 & 3.72 \\
\hline 8 & $\begin{array}{l}\text { I am able to work with } \\
\text { same groups members } \\
\text { again }\end{array}$ & 0 & 2 & 3 & $\begin{array}{l}1 \\
2\end{array}$ & 8 & 4.04 \\
\hline 9 & $\begin{array}{l}\text { I am able to give full } \\
\text { commitment to my group } \\
\text { members }\end{array}$ & 0 & 1 & 5 & $\begin{array}{l}1 \\
2\end{array}$ & 7 & 4.00 \\
\hline 10 & $\begin{array}{l}\text { I am comfortable to } \\
\text { assess the performance of } \\
\text { my peers adequately }\end{array}$ & 0 & 2 & 5 & $\begin{array}{l}1 \\
2\end{array}$ & 6 & 3.88 \\
\hline
\end{tabular}

(1=Strongly disagree; 2=Disagree; 3=Neutral; 4=Agree; $5=$ Strongly agree)

\section{Improve Student Self-Confident}

Findings showed majority of students positively feel that learning this two topic of Physics via PBL online help them improve not only in their individual or group learning process (mean=3.84), also their relationship in terms of cooperation within member in their learning group (mean=3.92). This also showed in their interview transcript:

Students: I am very conscious on voice out my opinion or suggestion before as I afraid if no one listening and responded to it, but through PBL online learning, I can post my opinion or suggestion anytime without being worried that no one listening or responded to it.

Students: PBL online learning helped me as I more confident in sharing what I've read, watch or heard to my friend.

\section{Improve Positive Relationship, Communication}

Students also find enjoy learning through PBL online (mean=4.08) and claimed help them increase the quality of their friendship (mean=4.16), and create friendship among them (mean=4.08). Study by [16] shows similar findings with implementation of online learning improve students' social presence.

Be it self-communication or among peers, students agreed that PBL online helped them create interaction among the members $($ mean=4.08) which similar with findings study by [17].

The positive findings show in aspect of students' relationship among peers and communication also supported with the next part of the findings where the statement mainly focus on students feedback regarding the possibility they will work together again in future. This is show when students agreed they able to work with the same members again (mean=4.04), beside that students also agreed able to give full commitment with their peers (mean=4.00) and students felt comfortable to assess the performance of their peers adequately (mean=3.88).

\section{Negative Findings: Room for Improvement in Future}

These part is to shows few vital factors contribute to students' self-readiness towards online learning and PBL in Physics. In terms of technical readiness, the obvious factor is internet connection. Due to lack of internet, students usually struggle to follow the discussion in real time, instead they have to reread all the contents and give response. This is indicated by their following interview transcript:

Students: It is really hard to follow if our internet connections wasn't good enough. Sometimes I can't join the discussion during provided time slot and I had to reread all my members' discussion later before giving an opinion or any additional information.

Students: PBL online was interesting as I don't have to rush my time at morning since I don't have to attend physical lecture class but sometimes I find online learning annoying me especially when it comes to internet connection during online discussion.

Study by [18] shows that this this factor can lead to students' motivation when flipped classroom adopted to a Physics course.

On pedagogical readiness which close related to facilitator, students shows unsatisfied behavior in their following interview transcript:

Students: The involvement of facilitator during slot discussion was a little lack, and this sometime make us a little lost during discussion. But the good thing is facilitator was reread all our discussion later and giving feedback on it, even it was a little late but at least it helps us later.

Students: I wish the involvement of facilitator during our slot discussion was more especially during the second phase of intervention. 
Students: The bad thing about online learning is that some of our friend was complaint about lack in internet connection, this sometime make the efficiency during slot discussion decreasing as sometime one or two of our member group couldn't attended the discussion during scheduled slot.

Facilitator or online instructor for online learning should be ready and fully equipped with training, pedagogical support from institute to train more online instructor also contributed to students' readiness towards online learning.

In contrast, few students understand the role of facilitator which only act as a guide during online learning. They stated that students on the other hand, is the one who responsible to be ready for the session themselves. Although, this is rarely happen among students as they prefer being ask and give by facilitator in traditional learning, this is show some of the students is really ready to swift from traditional method to online learning.

Students: Actually the involvement of facilitator during the slot discussion wasn't necessarily much as possible as I understand that facilitator just act as a guide during the whole discussion but I hope that our member group are as ready as possible during discussion. This is because it seem that our member doesn't even understand on simple derivation or calculation and this could make other members couldn't continue the discussion into more detail as we need to make other friend understand the simple calculation or derivation first.

As this PBL online was implemented into two different characteristics of subject in Physics, Statistical and Thermodynamics. Students finds easy and comfortable when PBL online was implemented in facts based of Physics such as Thermodynamics. However, for Statistical as it is mathematics based and required real time physical learning, PBL online is not a very good choice of learning method. This is shows from students' interview transcript:

Students: The thing that I found during this integrated PBL implemented in two different Physics courses is that in Thermodynamics, we could understand the fact that delivered more easily even without elementary explanation such as in lecture hall than in Statistical that require clarification and focus more particularly during the process of derivation process. This makes PBL online more appropriately applied in subjects that involves solution using fact than subject require additional understanding especially involving mathematical derivation and calculation.

Students: I think our group development was a little non-efficient during the second phase of integrated PBL implemented, this might due to Statistical course required us understanding more on one to one topic before we could be able to discuss it online.

\section{DISCUSSIONS}

The main reason to adopt the two (2) category for students' readiness from [8] is mainly due to the positive impact of

technical and pedagogical readiness to ensure successful online learning implementation, this is also happen on few previous study on what matters to make implementation of online learning success such as [19], [20] and [10].

Although it is strongly suggested that students' readiness is a key factor in the success of online learning implementation, the selection of suitable course for the implementation should goes hand in hand. For example, in this study, it was found that the subjects with mathematical backgrounds such as statistical physics became the element contributed to students inadequate to online learning. Nevertheless, this does not indicate the failure of online learning implementation for subjects with such nature, because previous studies as an example of proving the implementation of online learning in mathematical subjects can produce positive effects on students, on readiness and academic performance. Such example is show in study by [21], where significant increase on content understanding and positive perception when students of linear algebra course applied in flipped classroom. Similar findings shows in this study when students claimed to ready shifted their learning to online learning rather than stick with the norm.

\section{CONCLUSIONS}

Findings of this study suggest student is positively ready and adapted to PBL online activities as they aware the positive impact that bring along with online learning, in technical and pedagogical readiness, such as interactions and communication with their peer and lead to ability of them to give commitment. For future references and study, in order to implement success and effective PBL online activities primarily in Physics course, topic selection on which this PBL online implemented should be stressed. Hence, future study on implementation of online learning in such nature of Physic topics should expanded. Limitation great service of internet connection is other factor that should paid great attention as well as this will lead to students' satisfaction and positive acceptance towards this type of learning approach.

\section{ACKNOWLEDGMENT}

The publication of this study was funded from University Malaysia Sabah.

\section{REFERENCES}

1. Som Naidu, (2006). E-Learning: A Guidebook of Principles, Procedures and Practices. $2^{\text {nd }}$ Ed. Electronic Book. pp:1-2.

2. Swan, J.G. (2017). The Challenges of Online Learning Supporting and Engaging the Isolated Learner. Journal of Learning Design.

3. Oya, N.D., A. Iahad, Madar, M.J., \& Ab. Rahim, N. (2012). The Impact of E-Learning on Students Performance in Tertiary Institutions International Journal of Computer Networks and Wireless Communications. 2(2):121-130.

4. Balakrishnan, V., Teoh, K.K., Pourshafie, T., \& Liew, T.K. (2017). Social media and their use in learning: A comparative analysis between Australia and Malaysia from the learners' perspectives. Australasian Journal of Educational Technology. 33(1):81-97.

5. Lim, B.C.Y., Hong, K.S., and Tan, K.W. (2008). Acceptance of e-learning among distance learners: A Malaysian perspective Proceedings of Ascilite Melbourne 2008. 541-551. 
6. Nerantzi, C. (2012). A Case of Problem Based Learning for Cross-Institutional Collaboration. The Electronic Journal of e-Learning. 10(3):306-314.

7. Fauziah Sulaiman. (2011). Students' perceptions on the suitability of implementing an online problem-based learning in a physics course. Malaysian Journal of Educational Technology. 11(1):5-13.

8. Gay, G.H.E. (2016). An assessment of online instructor e-learning readiness before, during and after course delivery. Journal of Computing in Higher Education. 28(2): 199-220.

9. Iqbal, S., \& Ahmed Bhatti, Z. (2015). An Investigation of University Student Readiness towards M-learning using Technology Acceptance Model. The International Review of Research in Open and Distributed Learning. 16(4)

10. Yilmaz, R. (2017). Exploring the role of e-learning readiness on student satisfaction and motivation in flipped classroom. Journal of Computers in Human Behavior. 70:251-260.

11. Ceylanar, .S.G., \& Karakuș, F. (2018). Effects of The Flipped Classroom Model on Students' Self-Directed Learning Readiness and Attitudes Towards the English Course. Journal of English Language Teaching. 11(9).

12. Reine, D. \& Symons, S. (2005). Possibilities - a Practice Guide to Problem-based Learning in Physics \& Astronomy. Hull: University of Hull. 10(1):20-30.

13. Walsh, A. (2005). The Tutor in Problem Based Learning: A Novice's Guide. Canada: McMaster University-Faculty of Health Sciences.

14. Hurt, N.E., Larson, L.R., \& Prevost, L. (2016). Facebook as Online Teaching Tool: Effects on Students Participation, Learning, and Overall Course Performance. Journal of College Teaching. 64(2).

15. Jun Jin, Bridges, S.M., Botelho, M.G., \& Chan, L.K. (2015). Online Searching in PBL Tutorials. Interdisciplinary Journal of Problem-Based Learning. 9(1):13.

16. Borup, J., West, R.E., \& Graham, C.R. (2012). Improving online social presence through asynchronous video. Journal of Internet and Higher Education.15(2012):195-203.

17. Pepper, C. (2008). Implementing problem based learning in a science faculty. Issues in Educational Research. 18(1):60-72.

18. Assikoy, G., \& Özdamli, F. (2016). Flipped Classroom adapted to the ARCS Model of Motivation and applied to a Physics Course. Eurasia Journal of Mathematics, Science \& Technology Education 12(6):1589-1603

19. Hart, C. (2012). Factors Associated With Student Persistence in an Online Program of Study: A Review of the Literature. Journal of Interactive Online Learning. 11(1):19-42.

20. Stevenson, T. (2013). Online Student Persistence: What Matters is Outside the Classroom. Journal of Applied Learning Technology. 3(1):21-25.

21. Love, B., Hodge, A., Grandgenett, N., \& Swift, A.W. (2014). Student learning and perceptions in a flipped linear algebra course. International Journal of Mathematical Education in Science and Technology. 45(3):317-324.

\section{AUTHORS PROFILE}

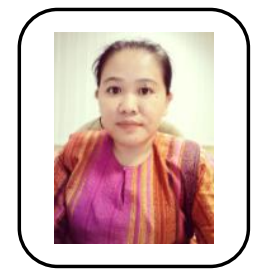

Elnetthra Folly Eldy is currently a lecturer in Universiti Malaysia Sabah teaching Physics for pre-university students. She graduated from Universiti Malaysia Sabah for her BSc in Physics with Electronics in 2011 and her MSc in Educational Technology on 2015. Her current interest in research is about student-centered learning, problem-based learning in a higher education institution and blended learning in higher learning. Her latest work is entitled Inverted Classroom Improves Pre-University Students Understanding On Basic Topic Of Physics: The Preliminary Study published in the Journal of Technology and Science Education, Optimisation Frequency for Different Lift off on Aluminium using Eddy Current Testing (ECT) Technique published in Transaction on Science and Technology both in 2019.

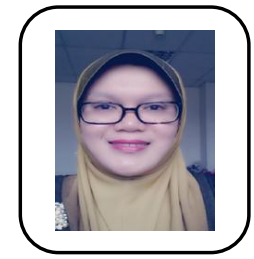

Fauziah Sulaiman was graduated from Universiti Sains Malaysia in 2002 with BSc. in Pure Physics and MA in Physics Education/Educational Technology. On 2011, she finishes her $\mathrm{PhD}$ in Physics Education from the University of Waikato, New Zealand and currently teaching Physics
(Thermodynamics and Statistical Physic) in Universiti Malaysia Sabah. Her current research work mainly about student-centered learning, problem-based learning in a higher education institution, science education in higher learning and non-destructive testing (NDT) in Physics. She is also a member of MyPBL and her latest work of publication is Optimal Frequency Design of Eddy Current Testing for Copper, Brass and Magnesium Alloy Metal with Difference Thickness published in the Global Journal of Engineering Science and Research Management. Another latest paper by Fauziah is The Effectiveness of Practical Work in Physics to Improve Students; Academic Performances published in International Journal of Social Sciences. 